\title{
The digital measurements for femoral prosthesis in a Turkish population
}

\author{
Barış Özgür Dönmez ${ }^{1}$, Bahadır Murat Demirel ${ }^{2}$, Umut Özsoy $^{3}$, Hakan Bilbaşar ${ }^{4}$, \\ Nurettin Oğuz ${ }^{3}$, Mustafa Ürgüden ${ }^{5}$ \\ ${ }^{1}$ Department of Nutrition and Dietetics, Antalya School of Health, Akdeniz University, Antalya, Turkey \\ ${ }^{2}$ Department of Anatomy, Faculty of Medicine, Ordu University, Ordu, Turkey \\ ${ }^{3}$ Department of Anatomy, Faculty of Medicine, Akdeniz University, Antalya, Turkey \\ ${ }^{4}$ Department of Orthopedics and Traumatology, Akdeniz Hospital, Manavgat, Antalya, Turkey \\ 'Department of Orthopedics and Traumatology, , Faculty of Medicine, Akdeniz University, Antalya, Turkey
}

\begin{abstract}
Objectives: This study was designed (i) to evaluate the angle between anatomical and mechanical axes of the femur and (ii) to compare shaft curve of the femur according to anatomical axis of femur with curve of the four femoral nail used in a Turkish population, in order to determine the safety degrees of distal femoral valgus cut for a routine surgical procedures.

Methods: Sixty-six right femurs, 68 left femurs and 4 femoral nails were measured. We measured the angle between anatomical axis and mechanical axis, the shaft curve of the femur according to anatomical axis on the femurs and shaft curve of the femoral nail on 4 femoral nails, which are commonly used in Turkey, using a digitizer system.

Results: In the 66 right femurs, the mean values of the angle between anatomical axis and mechanical axis was calculated as $6.386 \pm 0.820^{\circ}$ and the mean value of the shaft curve of the femur according to anatomical axis was calculated as $16.713 \pm 2.371^{\circ}$. In the 68 left femurs, the mean value of angle between anatomical axis and mechanical axis was calculated as $6.915 \pm 0.712^{\circ}$ and the mean value of the shaft curve of the femur according to anatomical axis was calculated as $16.148 \pm 2.689^{\circ}$. We calculated that curve of the 4 nails were Hipokrat $8.65^{\circ}$, Trigen $10.20^{\circ}$, Ortopro $6.38^{\circ}$ and Recon $8.70^{\circ}$, respectively.
\end{abstract}

Conclusion: According to our results, new nails should be designed in the light of anatomical studies for each population. This will reduce the complications during surgery.

Key words: anatomical axes; cutting guide; femoral curve; femoral nail; mechanical axes

Anatomy 2012-2013;6-7:58-62, ( 2012-2013 TSACA

\section{Introduction}

Femur is one of the bones in human that exhibit ethnic, racial and gender differences. ${ }^{[1-3]}$ Some clinical studies explained these variations ${ }^{[1,3,4]}$ and several studies concerning the anatomy and functional axes of femur have previously been made on normal femur. ${ }^{[5-11]}$ For intraoperative referencing, several anatomical landmarks concerning femur are used by surgeons. ${ }^{[12]}$ Especially, ideal lower extremity mechanical axis alignment is important for success of total knee arthroplasty. The angle between the anatomical axis (AAx) and the mechanical axis (MAx) of the femur determines the axial alignment of limb and is used to determine the angle of resection of distal femur in total knee arthroplasty. ${ }^{[13]}$ Additionally, total knee arthroplasty systems include that femurs have an anatomic-mechanical axis variation of $5^{\circ}$ and $6^{\circ}$ which have a fixed cutting guide that is generally used an instrument for knee arthroplasty. ${ }^{[13-15]}$

The angle between anatomical and mechanical axis is very important for arrange distal femoral cut. Kharwadkar et al. ${ }^{[13]}$ measured aranging the angle between anatomical and mechanical axes in 83 consecutive patients. They sug- 
gested that routine practice of selecting $5^{\circ}$ and $6^{\circ}$ of the distal femoral cut for an uncomplicated primary total knee arthroplasty was safe ${ }^{[13]}$ On the other hand, intramedullar nailing of femur is important for of diaphyseal femur fracture. ${ }^{[1,16-18]}$ If there is a mismatch between curvature of the intramedullary nails and the anterior bowing of the femur several problems may arise like angular defects, iatrogenic fractures and penetration of the distal anterior femoral cortical bone. ${ }^{[1,16]}$ Several basic and clinical studies were conducted to determine the compatibility of femoral medulla with intramedullary nails because intramedullary nailing is currently accepted as the gold standard in the treatment of diaphyseal femur fractures. ${ }^{[1,16]}$

The goal of the present study is (i) to analyses the variation in the angle between anatomical and mechanical axes of the femur and to determine the safety degrees of distal femoral valgus cut for a routine surgical procedures, (ii) to evaluate shaft curve of the femur according to anatomical axis of femur and to compare with curve of the femoral nail in used in Turkish population.

\section{Materials and Methods}

In the present study, 66 femurs right side and 68 femurs left side from the bone collection of Akdeniz University, School of Medicine, Department of Anatomy and 4 femoral nails, which are commonly used in Turkey, Trigen (Smith \& Nephew, Inc., Andover, MA, USA), Hipokrat (Hipokrat AŞ, Izmir, Turkey), Ortopro (Ortopro A.Ş., Istanbul, Turkey) and Recon (Stryker Corp., Kalamazoo, MI, USA) were measured.

\section{Bone measurement}

We measured (i) the angle between AAx and MAx and (ii) the shaft curve of the femur (CF) according to AAx (Figure 1), using MicroScribe G2X (Immersion Corp., San Jose, CA, USA) digitizer, the accuracy of the device is confirmed by previous study ${ }^{[19]}$ and the data were obtained by Surfcam Velocity software (Surfware Inc., Camarillo, CA, USA) (Figure 2).

\section{Femoral nails measurement}

In these measurements, 4 femoral nails, which are commonly used in Turkey, Trigen, Hipokrat, Ortopro and Recon were measured. We measured the shaft curve of the femoral nail with using MicroScribe G2X.

MicroScribe G2X is a $3 \mathrm{D}$ digitizer that has a mechanical arm with a stylus. Additionally, it has an accuracy of up to 0.009 inches and sampling speeds of as much as $1000 \mathrm{~Hz}$.

Before measurement, all femurs were fastened to the clamp and examiner could be reach any landmark on femurs (Figure 3).

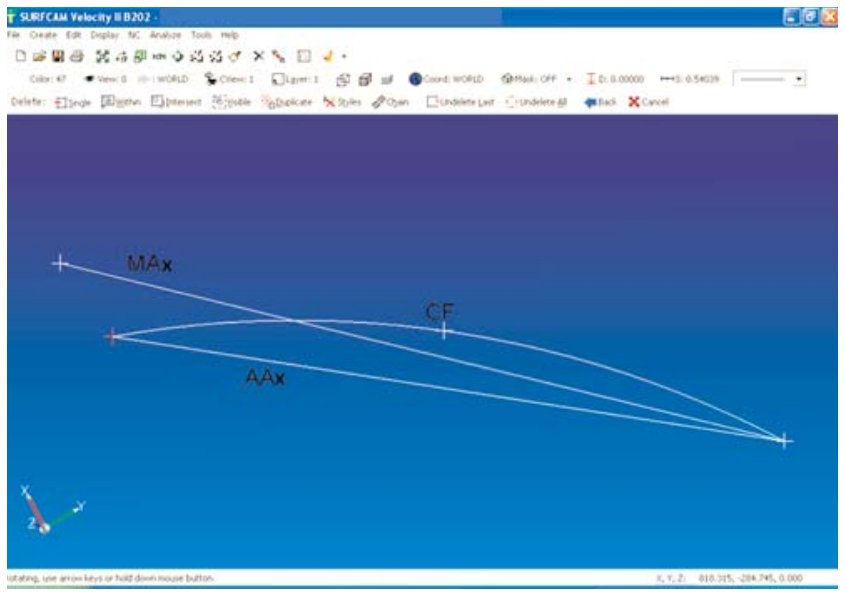

Figure 1. View of the microscribe software. AAx: a natomical axis; CF: shaft curve of the femur; MAx: mechanical axis.

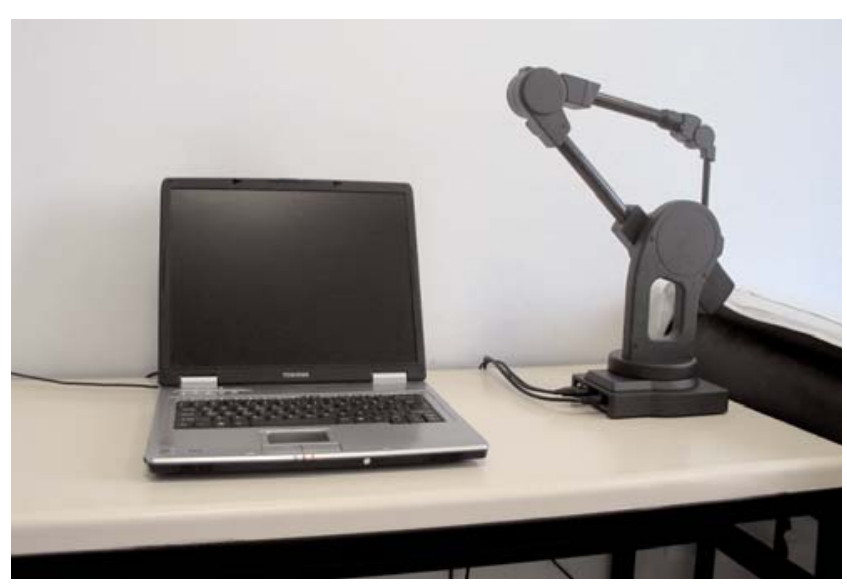

Figure 2. Microscribe digitizing system.

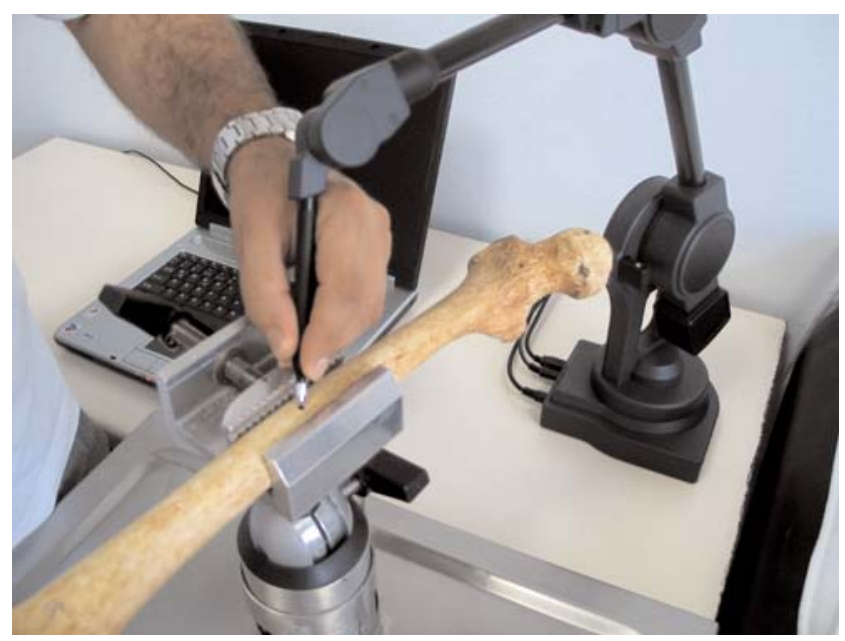

Figure 3. Measurements performed by microsicribe digitizing system on femur fixed with clamp. 
Before measurements all femurs were pointed out with a pen and fastened to the clamp so that the examiners could reach any landmark on femurs (Figure 4). To evaluate the angle between the anatomical and mechanical axis; the center of the piriform fossa (i) and the superomedial point of the insertion of the posterior cruciate ligament (ii), the center of the head of the femur (iii) were used as landmarks respectively. The curve of the femoral shaft was drawn by use of the points between the center of the piriform fossa, the center point of the shaft of the femur (iv) and the superomedial point of the insertion of the posterior cruciate ligament and it was evaluated according to the AAx. Data collection with digitizer was performed by use of these landmarks by three observers individually and means values were calculated for results (Table 1).

\section{Results}

In the 66 right femurs, the mean values of the angle between AAx and MAx was calculated as $6.386 \pm 0.820^{\circ}$ and the mean value of the shaft curve of the femur (CF) according to AAx was calculated as $16.713 \pm 2.371^{\circ}$ (Table 2).

In the 68 left femurs, the mean value of angle between AAx and MAx was calculated as $6.915 \pm 0.712^{\circ}$ and the mean value of the shaft curve of the femur (CF) according to AAx was calculated as $16.148 \pm 2689^{\circ}$ (Table 3).
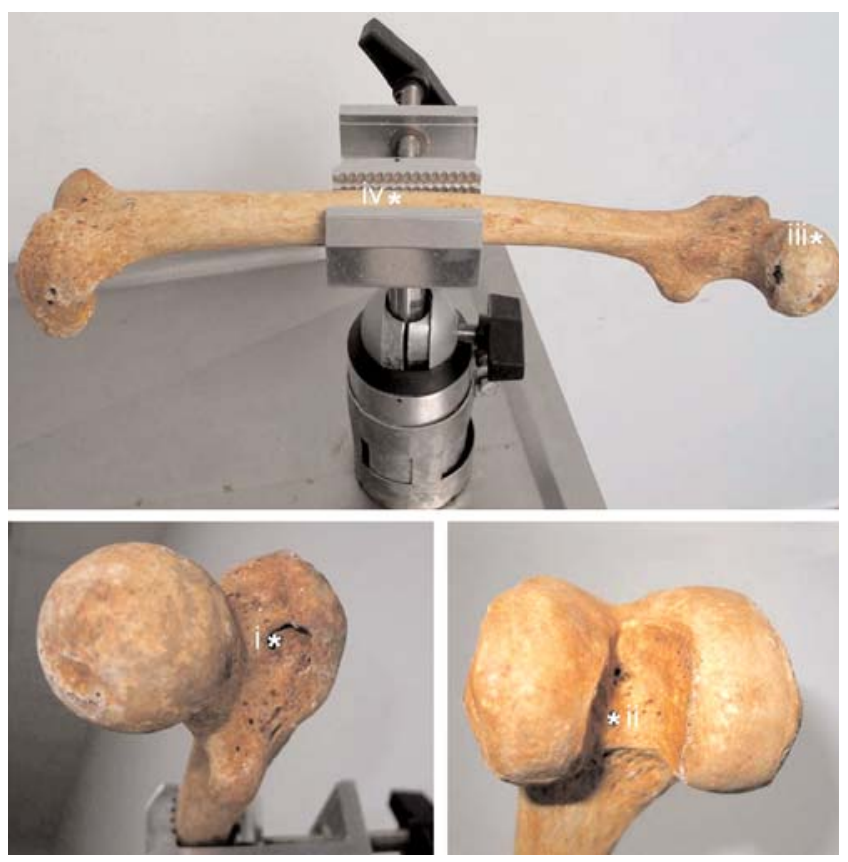

Figure 4. Pointed landmarks on femur. i: center of the piriform fossa; ii: superomedial point of the insertion of the anterior cruciate ligament; iii: the center of the head of the femur; iv: the center point of the shaft of the femur.
The curve of the four nails were measured as Hipocrat $8.65^{\circ}$, Trigen $10.20^{\circ}$, Ortopro $6.38^{\circ}$ and Recon $8.70^{\circ}$, respectively (Table 4).

\section{Discussion}

In our study, the mean value of the between $\mathrm{AAx}$ and MAx was calculated as $6.386 \pm 0.820^{\circ}$ and $6.915 \pm 0.712^{\circ}$ in the right and the left femurs, respectively. The same parameter was calculated as $5.4^{\circ} \pm 0.9^{\circ}$ by Kharwadkar et al. in 83 consecutive patients in random British popula-

Table 1

Chosen landmarks on femur

\begin{tabular}{ll}
\hline Landmarks / Plane & Description \\
\hline I & Center of the piriform fossa \\
ii & $\begin{array}{l}\text { Superomedial point of the insertion of the } \\
\text { posterior cruciate ligament }\end{array}$ \\
iii & The center of the head of the femur \\
iv & The center point of the shaft of the femur \\
\hline
\end{tabular}

Table 2

Results of measurements performed on right-sided femurs $\mathrm{n}=66$ (right)

\begin{tabular}{lcccc}
\hline Landmarks & Minimum & Maximum & Mean & SD \\
\hline AAx - MAx & $4.350^{\circ}$ & $7.970^{\circ}$ & $6.386^{\circ}$ & $0.820^{\circ}$ \\
CF - AAx & $11.460^{\circ}$ & $22.480^{\circ}$ & $16.713^{\circ}$ & $2.371^{\circ}$ \\
\hline
\end{tabular}

Table 3

Results of measurements performed on left sided femurs $\mathrm{n}=68$ (left)

\begin{tabular}{lcccc}
\hline Landmarks & Minimum & Maximum & Mean & SD \\
\hline AAx - MAx & $5.480^{\circ}$ & $8.490^{\circ}$ & $6.915^{\circ}$ & $0.712^{\circ}$ \\
CF - AAx & $7.930^{\circ}$ & $26.250^{\circ}$ & $16.148^{\circ}$ & $2.689^{\circ}$ \\
\hline
\end{tabular}

Table 4

Results of measurements performed on femoral nails

Curve of the femoral nails $(n=4)$

\begin{tabular}{lc} 
Hipokrat & $8.65^{\circ}$ \\
Trigen & $10.20^{\circ}$ \\
Ortopro & $6.38^{\circ}$ \\
Recon & $8.70^{\circ}$ \\
\hline
\end{tabular}


tion. ${ }^{[13]}$ They suggested that age, gender and the laterality of the limb did not cause any significant difference on this angle in their study and routine practice of selecting $5^{\circ}$ and $6^{\circ}$ of the distal femoral cut for an uncomplicated primary total knee arthroplasty was safe. ${ }^{[13]}$ In another study, Dunn et al. informed that all the femurs had an anatomic-mechanical axis variation of $5^{\circ}$ and $6^{\circ}$ and had a fixed cutting guide. ${ }^{[20]}$ In our study, we found the same parameter as $6.386 \pm 0.820^{\circ}$ and $6.915 \pm 0.712^{\circ}$ in the right and the left femurs, respectively. Our results revealed that wider angle of valgus cut of the distal femur for reconstructive surgical procedures should be more safe in Turkish population.

Closed intramedullary nailing of femoral shaft fractures is the gold standard of treatment. ${ }^{[2]]}$ In the presences of an uncompensated mismatch between the curve of a femoral nail and the femoral medullary bowing, serious problems may arise. ${ }^{[1]}$ An iatrogenic fracture may develop during femoral nailing. The nail may rip the distal anterior cortex of the femur during femoral nailing. ${ }^{[1,18,22]}$ Additionally, mismatch of the nail, curve of the femur cause inadequate contact of the fracture ends and it leads to new problems. ${ }^{[1,21]}$ The insertion process may become difficult as an inappropriately curved nail leans against the medullary wall. ${ }^{[1,22,23]}$ Ideal-entering point is about $1 \mathrm{~cm}$ front of the posterior cruciate ligament. If intramedullar guide settle in this ideal entering point, prosthesis may provide a better suitable settle in anterior and posterior plan. Femoral sagittal bowing is very important for total knee arthroplasty but it has not been well discussed in the literature. ${ }^{[2]]}$ In our study, the mean value of the $\mathrm{CF}$ according to $\mathrm{AA}$ was calculated as $16: 713 \pm 2.371^{\circ}$ and $16.148 \pm 2.689^{\circ}$ in the right and the left femurs, respectively. We measured the curve of the four nails as Hipokrat $8.65^{\circ}$, Trigen $10.20^{\circ}$, Ortopro $6.38^{\circ}$ and Recon $8.70^{\circ}$, respectively. We compared the curve of the most used four nails in Turkey and found that the curve of the nails were lower than the curve of the femur shaft of the Turkish population. According to our results, more curved nails should be designed. These new designed nails will be more suitable for Turkish population. We think that these new designed nails will provide less problems during surgical operations.

\section{Conclusion}

In conclusion, each population has different anatomical specialty. According to our results, new nails should be designed in the light of anatomical studies for each population. This will reduce the complications during surgery.

\section{References}

1. Harma A, Germen B, Karakas HM, Elmali N, Inan M. The comparisn of femoral curves and curves of contemporary intramedullary nails. Surg Radiol Anat 2005;27:502-6.

2. Dittmar M. Functional and postural lateral preferences in humans: interrelations and life-span age differences. Hum Biol 2002;74:569-85.

3. Gill GW. Racial variation in the proximal and distal femur: heritability and forensic utility. J Forensic Sci 2001;46:791-9.

4. Ballard ME. Anterior femoral curvature revisited: race assessment from the femur. J Forensic Sci 1999;44:700-7.

5. Poilvache PL, Insall JN, Scuderi GR, Font-Rodriguez DE. Rotational landmarks and sizing of the distal femur in total knee arthroplasty. Clin Orthop Relat Res 1996;(335):35-46.

6. Berger RA, Rubash HE, Seel MJ, Thompson WH, Crossett LS. Determining the rotational alignment of the femoral component in total knee arthroplasty using the epicondylar axis. Clin Orthop Relat Res 1993;(286):40-7.

7. Kurosawa H, Walker PS, Abe S, Garg A, Hunter T. Geometry and motion of the knee for implant and orthotic design. J Biomech 1985;18:487-99.

8. Mantas JP, Bloebaum RD, Skedros JG, Hofmann AA. Implications of reference axes used for rotational alignment of the femoral component in primary and revision knee arthroplasty. J Arthroplasty 1992;7:531-5.

9. Mensch JS, Amstutz HC. Knee morphology as a guide to knee replacement. Clin Orthop Relat Res 1975;(112):231-41.

10. Seedhom BB, Longton EB, Wright V, Dowson D. Dimensions of the knee. Radiographic and autopsy study of sizes required by a knee prosthesis. Ann Rheum Dis 1972;31:54-8.

11. Yoshioka Y, Siu D, Cooke TD. The anatomy and functional axes of the femur. J Bone Joint Surg Am 1987;69:873-80.

12. Stoeckl B, Nogler M, Krismer M, Beimel C, de la Barrera JL, Kessler O. Reliability of the transepicondylar axis as an anatomical landmark in total knee arthroplasty. J Arthroplasty 2006;21:87882 .

13. Kharwadkar N, Kent RE, Sharara KH, Naique S. 5 degrees to 6 degrees of distal femoral cut for uncomplicated primary total knee arthroplasty: is it safe? Knee 2006;13:57-60.

14. Bardakos N, Cil A, Thompson B, Stocks G. Mechanical axis cannot be restored in total knee arthroplasty with a fixed valgus resection angle: a radiographic study. J Arthroplasty 2007;22:85-9.

15. McGrory JE, Trousdale RT, Pagnano MW, Nigbur $M$. Preoperative hip to ankle radiographs in total knee arthroplasty. Clin Orthop Relat Res 2002;(404):196-202.

16. Gausepohl T, Pennig D, Koebke J, Harnoss S. Antegrade femoral nailing: an anatomical determination of the correct entry point. Injury 2002;33:701-5.

17. Steriopoulos K, Psarakis SA, Savakis C, Papakitsou E, Christakis D, Velivasakis E. Architecture of the femoral medullary canal and working length for intramedullary nailing. Biomechanic indications for dynamic nailing. Acta Orthop Scand Suppl 1997;275:123-6.

18. Harper MC, Carson WL. Curvature of the femur and the proximal entry point for an intramedullary rod. Clin Orthop Relat Res 1987;(220):155-61.

19. Ozsoy U, Demirel BM, Yildirim FB, Tosun O, Sarikcioglu L. Method selection in craniofacial measurements: advantages and 
disadvantages of 3D digitization method. J Craniomaxillofac Surg 2009;37:285-90.

20. Dunn HK GV, Krackow KA. Instructional course lectures. Primary total knee arthroplasty: surgical technique and principles. In: Proceedings of the 68th Annual Meeting of the American Academy of Orthopaedic Surgeons, San Francisco, CA, February 28-March 4, 2001. p. 1-4.

21. Ricci WM, Bellabarba C, Lewis R, et al. Angular malalignment after intramedullary nailing of femoral shaft fractures. J Orthop Trauma 2001;15:90-5.
22. Leung KS, Procter P, Robioneck B, Behrens K. Geometric mismatch of the Gamma nail to the Chinese femur. Clin Orthop Relat Res 1996;(323):42-8.

23. Egol KA, Chang EY, Cvitkovic J, Kummer FJ, Koval KJ. Mismatch of current intramedullary nails with the anterior bow of the femur. J Orthop Trauma 2004;18:410-5.

24. Tang WM, Chiu KY, Kwan MF, Ng TP, Yau WP. Sagittal bowing of the distal femur in Chinese patients who require total knee arthroplasty. J Orthop Res 2005;23:41-5.

Correspondence to: Barış Özgür Dönmez, PhD

Department of Nutrition and Dietetics, Akdeniz University, Antalya School of Health, Antalya, Turkey

Phone: 00902422496989 Fax: 00902422274485

e-mail: barisozgurdonmez@hotmail.com

Conflict of interest statement: No conflicts declared. 